\title{
Self-efficacy, self-esteem, achievement motivation and academic achievement among students in public and private higher institutions
}

\begin{abstract}
This study examines the differences in academic performances between students from the Public Higher Institutions and the Private Higher Institutions. Sanchez (2006) reported that public schools perform favorably with private schools when students' income and socioeconomic status are taken into account The findings counter a popularly held notion, that private schools outperform public schools. Another finding by The Center on Education Policy (CEP) (2007) also indicated that private school students and public school students perform equally on achievement tests. However this study conducted on 647 second year students in two public and two private universities in Malaysia finds that students from the Public Higher Institutions perform better academically (Mean $=3.25, \mathrm{SD}=0.38$ ) as compared to students from the Private Higher Institutions ( Mean =3.05, SD =0.47). The students from the Public Higher Institutions seemed to do better. Hence this study also looked into some psychosocial factors (Self-efficacy, Self-esteem and Achievement Motivation ) that may lead into the explanations on the differences.. The findings are further discussed.
\end{abstract}

Keyword: Self Efficacy, Self Esteem, Achievement Motivation, Academic Achievement 